\title{
A Friendly Relationship between Endophytic Fungi and Medicinal Plants: A Systematic Review
}

\author{
Min Jia ${ }^{1+}$, Ling Chen ${ }^{1+}$, Hai-Liang Xin ${ }^{1}$, Cheng-Jian Zheng ${ }^{1}$, Khalid Rahman ${ }^{2}$, Ting Han ${ }^{1 *}$ \\ and Lu-Ping Qin ${ }^{1 *}$ \\ 1 Department of Pharmacognosy, School of Pharmacy, Second Military Medical University, Shanghai, China, ${ }^{2}$ Department of \\ Physiological Biochemistry, School of Pharmacy and Biomolecular Sciences, Liverpool John Moores University, Liverpool, UK
}

Endophytic fungi or endophytes exist widely inside the healthy tissues of living plants, and are important components of plant micro-ecosystems. Over the long period of evolution, some co-existing endophytes and their host plants have established a special relationship with one and another, which can significantly influence the formation of metabolic products in plants, then affect quality and quantity of crude drugs derived from medicinal plants. This paper will focus on the increasing knowledge of relationships between endophytic fungi and medicinal plants through reviewing of published research data obtained from the last 30 years. The analytical results indicate that the distribution and population structure of endophytes can be considerably affected by factors, such as the genetic background, age, and environmental conditions of their hosts. On the other hand, the endophytic fungi can also confer profound impacts on their host plants by enhancing their growth, increasing their fitness, strengthening their tolerances to abiotic and biotic stresses, and promoting their accumulation of secondary metabolites. All the changes are very important for the production of bioactive components in their hosts. Hence, it is essential to understand such relationships between endophytic fungi and their host medicinal plants. Such knowledge can be well exploited and applied for the production of better and more drugs from medicinal plants.

tThese authors have contributed equally to this work.

Specialty section: This article was submitted to Plant Biotic Interactions, a section of the journal Frontiers in Microbiology

Received: 25 November 2015 Accepted: 26 May 2016

Published: 09 June 2016

Citation: Jia $M$, Chen L, Xin H-L, Zheng C-J, Rahman K, Han T and Qin L-P (2016)

A Friendly Relationship between Endophytic Fungi and Medicinal Plants: A Systematic Review.

Front. Microbiol. 7:906.

doi: 10.3389/fmicb.2016.00906
Keywords: endophytic fungi, medicinal plant, population structure, plant-microbe interaction, secondary metabolite

\section{INTRODUCTION}

It is widely considered in a conventional view that the quality and quantity of crude drugs originated from medicinal plants are largely affected by such factors as the genetic background of the concerned plants, ecological habitats where the plants live, and soil nutrients (Dai et al., 2003; Sherameti et al., 2005). However, in the recent years, it is gradually recognized that endophytic fungi or endophytes have played a very important role in affecting the quality and quantity of the crude drugs through a particular fungus-host interaction, indicating that more understanding on the particular relationships between endophytic fungi and medicinal plants is required for promoting crude drug production (Faeth and Fagan, 2002). Although endophytic fungi are one of the most important elements in plant micro-ecosystems that should have significant influences on the growth and development of host plants, our knowledge about the exact relationships between endophytic fungi and their host plants is still very limited. Understanding and exploiting 
such relationships will facilitate the ideal production of better drugs by manipulating the growth conditions of medicinal plants by, for example, adding a particular group of endophytic fungi to the plants to improve the drug quality and quantity (Firáková et al., 2007). Ideally, an alternative method can be developed to directly produce desired drugs through bioengineering of the selected medicinal plants and endophytic fungi under a certain cultural condition, if the fungus-host relationships and their metabolic mechanisms under cultural conditions are well understood (Kumaran et al., 2008, 2009). Such an industry style of manufacture may replace the traditional way to produce drugs, which essentially depends on natural medicinal plants.

Endophytic fungi belong to mitosporic and meiosporic ascomycetes that "asymptomatically reside in the internal tissues of plants beneath the epidermal cell layer, where they colonize healthy and living tissue via quiescent infections" (Bacon and White, 2000). There is a great biological diversity of endophytic fungi, occurring naturally in the temperate regions and tropical rainforests, where about 300,000 terrestrial host-plant species are distributed. Each plant species hosts one or more endophytic fungus species. Endophytic fungi are diverse polyphyletic groups of microorganisms, and can thrive asymptomatically in different healthy tissues of living plants above and/or under the ground, including stems, leaves, and/or roots. It is estimated that over one million endophytic fungal species occurring in the nature (Faeth and Fagan, 2002). Schultz classified the fungal endophytic fungi into three main ecological groups: (a) mycorrizal; (b) balansicaeous or pasture endophytic fungi; and (c) non pasture endophytic fungi (Faeth and Fagan, 2002). The bioactive compounds produced by endophytic fungi, exclusive of those to their host plants, are very important to increase the adaptability of both endophytic fungi and their host plants, such as the tolerances to biotic and abiotic stresses. In addition, these compounds can induce the production of a plethora of known and novel biologically active secondary metabolites (Zhang et al., 2006; Firáková et al., 2007; Rodriguez et al., 2009) that can be exploited and applied by human as important medicinal resources.

It is known that the colonization of endophytic fungi is not an incidental opportunity because of the chemotaxis that is specific chemicals produced by the host plants. At the same time, different types of secondary metabolites, such as saponin and essential oils from medicinal plants, are produced through long-term co-evolution as a resistance mechanism to the pathogens, most possibly including endophytic fungi. Therefore, the secondary metabolites became obstacles for the colonization of endophytic fungi. To overcome this, endophytic fungi must secrete the matching detoxification enzymes, such as cellulases, lactase, xylanase, and protease, to decompose these secondary metabolites before they penetrate through the defense systems of the resided host-plants. Once inside the tissues of a hostplant, the endophytic fungi assumed a quiescent (latent) state, either for the whole lifetime of the host plant (neutralism) or for an extended period of time (mutualism or antagonism) until environmental conditions are favorable for endophytic fungi or the ontogenetic state of the host changes to the advantage of the fungi (Sieber, 2007).
During the long period of co-existence and evolutionary processes, different relationships have been established between endophytic fungi and their host plants through a particular fungus-host interaction recognized as: (i) a continuum of mutualism, (ii) antagonism, and (iii) neutralism. The genetic background, nutrient level, and ecological habitats of the medicinal host plants are considered as the pressure-choice factors on the population structure of the endophytic fungi that, in turn, confer some kinds of benefits, such as the induced growth, increased resistance to disease, and/or herbivore (Rodriguez et al., 2009), as well as accumulated bioactive components (Firáková et al., 2007), some of which can be used by human as beneficial medicines. Therefore, the mutual interrelation between endophytic fungi and their host plants can impose certain effects on the formulation of some types of bioactive compounds that can be used by human.

In this paper, we reviewed the studies of endophytic fungi and medicinal plants for the last 30 years, with a particular emphasis on the factors that possibly influence the population structure and distribution of endophytic fungi and benefits to their host plants from the existence of endophytic fungi. We hope that this review will provide readers useful information for understanding the environmental and host-plant factors affecting endophytic fungi as well as the friendly relationships between endophytic fungi and medicinal plants, which may help researchers make better use of the beneficial symbiosis and expand the way for obtaining high-quality resources of certain medicinal plants. Ideally, a system mimicking the mutualistic or antagonistic symbiosis conditions of endophytic fungi and their host plants may be established to effectively produce the desired drug compounds through bioengineering, if the relationships and conditions that promote the production of the compounds are clearly understood. This review will also discuss the existing problems in research and potential applications of endophytic fungi for drug production.

\section{ENVIRONMENTAL AND HOST-PLANT FACTORS AFFECTING ENDOPHYTIC FUNGI}

Results of the analyses also indicated that the population structure or distribution pattern of endophytic fungi was significantly associated with the variation in environments, as well as the classification and genetic background of host plants (Table 1, Figure 1A). Data from the reference analysis suggested that some environmental conditions, such as temperature, humidity, illumination, geographic location, and vegetation significantly affected the distribution pattern of endophytic fungi (Suryanarayanan et al., 2005; Song et al., 2007). For example, particular conditions determined the distribution ranges of host plants that in return determine the species of endophytic fungi and their spore germination, growth, reproduction, and metabolism during the entire life cycle. Similarly, results from the analyses suggested that the distribution of certain endophytic fungal populations was only restricted to 
TABLE 1 | Influences of host medicinal plants on the population structure of endophytic fungi.

\begin{tabular}{|c|c|c|c|c|}
\hline $\begin{array}{l}\text { Family of host plants } \\
\text { (represent species) }\end{array}$ & Isolation part & Habitat & $\begin{array}{l}\text { Factor affecting the } \\
\text { population structure }\end{array}$ & References \\
\hline Cactaceae (Cactus sp.) & Stem & Desert of tropical savanna & $\begin{array}{l}\text { Environment: moisture }{ }^{\mathrm{a}} \text { and } \\
\text { temperature }^{\mathrm{b}}\end{array}$ & Suryanarayanan et al., 2005 \\
\hline $\begin{array}{l}\text { Rosaceae (Malus } \\
\text { domestica) }\end{array}$ & Leaf, flower, fruit & Tropical rainy region & Environment: cultivation style ${ }^{c}$ & Camatti-Sartori et al., 2005 \\
\hline $\begin{array}{l}\text { Leguminosae (Glycyrrhiza } \\
\text { inflat) }\end{array}$ & Root & $\begin{array}{l}\text { Salinized sandy land in warm } \\
\text { temperate region }\end{array}$ & $\begin{array}{l}\text { Environment: moisture }{ }^{\mathrm{a}} \text { and } \\
\text { temperature }^{\mathrm{b}}\end{array}$ & Song et al., 2007 \\
\hline $\begin{array}{l}\text { Eucommiaceae (Eucommia } \\
\text { ulmoides) }\end{array}$ & Leaf, branch, bark & $\begin{array}{l}\text { Subtropical mountain and warm } \\
\text { temperate semi-humid region }\end{array}$ & $\begin{array}{l}\text { Environment: latitude }{ }^{\mathrm{e}} \text { and } \\
\text { temperature }^{\mathrm{b}} \\
\text { Tissue }^{\mathrm{d}}\end{array}$ & Sun J. et al., 2008 \\
\hline $\begin{array}{l}\text { Orchidaceae (Gastrodia } \\
\text { elata) }\end{array}$ & Tuber, flower & $\begin{array}{l}\text { Hillside forests, wetland in } \\
\text { temperate plateau }\end{array}$ & $\begin{array}{l}\text { Enviroment: latitude } \\
\text { Tissue }^{\mathrm{d}}\end{array}$ & Mo et al., 2008 \\
\hline $\begin{array}{l}\text { Euphorbiaceae (Sapium } \\
\text { sebiferum) }\end{array}$ & Leaf, twig & Mountain in subtropics & $\begin{array}{l}\text { Genetic background }^{f} \\
\text { Tissue }^{d}\end{array}$ & Dai et al., 2003 \\
\hline $\begin{array}{l}\text { Smilacaceae (Heterosmilax } \\
\text { japonica) }\end{array}$ & Stem & Subtropical monsoon region & Seasong & Gao et al., 2006 \\
\hline $\begin{array}{l}\text { Pinaceae (Pinus } \\
\text { tabulaeformis) }\end{array}$ & Bark, needle, xylem & $\begin{array}{l}\text { Forests in warm temperate } \\
\text { semi-humid monsoon region }\end{array}$ & Seasong & Guo et al., 2008 \\
\hline & & & Tissue age $^{h}$ & \\
\hline Teaceae (Camellia japonica) & Leaf & Temperate secondary forest & $\begin{array}{l}\text { Seasong } \\
\text { Tissue age }^{\text {h }}\end{array}$ & Osono, 2008 \\
\hline $\begin{array}{l}\text { Umbelliferae (Apium } \\
\text { graveolens, Cichorium } \\
\text { intybus, Foeniculum } \\
\text { vulgare, Lactuca sativa) }\end{array}$ & Leaf, root, seed & Mediterranean region & Taxonomy of plants ${ }^{f}$ & D'Amico et al., 2008 \\
\hline $\begin{array}{l}\text { Zingiberaceae (Amomum } \\
\text { siamense) }\end{array}$ & Leaf, pseudostem, rhizome & Tropical monsoon forest & Tissue $^{d}$ & Bussaban et al., 2001 \\
\hline $\begin{array}{l}\text { Compositae (Atractylodes } \\
\text { lancea) }\end{array}$ & Rhizome & Mountain in subtropics & Tissue $^{d}$ and age of tissue ${ }^{h}$ & Wang Y. et al., 2009 \\
\hline $\begin{array}{l}\text { Asclepiadaceae (Calotropis } \\
\text { procera) }\end{array}$ & Leaf & Garden bed & Tissue $^{d}$ & Nascimento et al., 2015 \\
\hline
\end{tabular}

a The endophyte colonization was positively correlated with humidity.

${ }^{b}$ The lower species diversity of the endophyte in temperate plants than that in tropical forests trees.

${ }^{c}$ The highest endophytes number under organic cultivation.

${ }^{d}$ The colonization rates of endophytic fungi from high to low in different tissues were bark $>$ needle $>x y l e m$.

${ }^{e}$ Different dominant endophytic fungi.

${ }^{f}$ Specific host-endophyte combinations.

${ }^{g}$ The colonization rates of endophytic fungi from high to low were spring $>$ winter $>$ autumn $>$ summer.

${ }^{h}$ The species richness of endophytic fungi increased as tissue aged, especially leaves.

particular host plant species (or families) and particular genetic background (genotypes) of a species (Dai et al., 2003; D'Amico et al., 2008). This finding is particularly important because the non-random distribution of endophytic fungi will determine the production of diverse secondary metabolites promoted by endophytic fungi that can be used by human as drugs. In addition, the secondary metabolites may confer different benefits to the host plants, such as enhancing the growth and resistance to biotic and abiotic stresses, which provides opportunities for us to understand the relationships between endophytic fungi and medicinal plants. Below, we would present the influences of ecological environments and genetic background/tissues of host plants on the population structure of endophytic fungi, respectively.

\section{Influences of Ecological Environments on Population Structure of Endophytic Fungi}

We found that ecological or environmental conditions, such as temperature, humidity, and levels of soil nutrition were important factors to determine the types and amount of secondary metabolites of the host plants, which would indirectly affect the population structure of the endophytic fungi. For example, under the conditions of low mean annual sunshine hour and the high mean annual humidity, the host medicinal plants would produce more nutrients that were suitable for the colonization, reproduction, and dissemination of the endophytic fungi (Wu et al., 2013). In contrast, under the cold climatic conditions and inappropriate rates of respiration, oxygen concentration, and $\mathrm{pH}$ value, only certain types of host species 


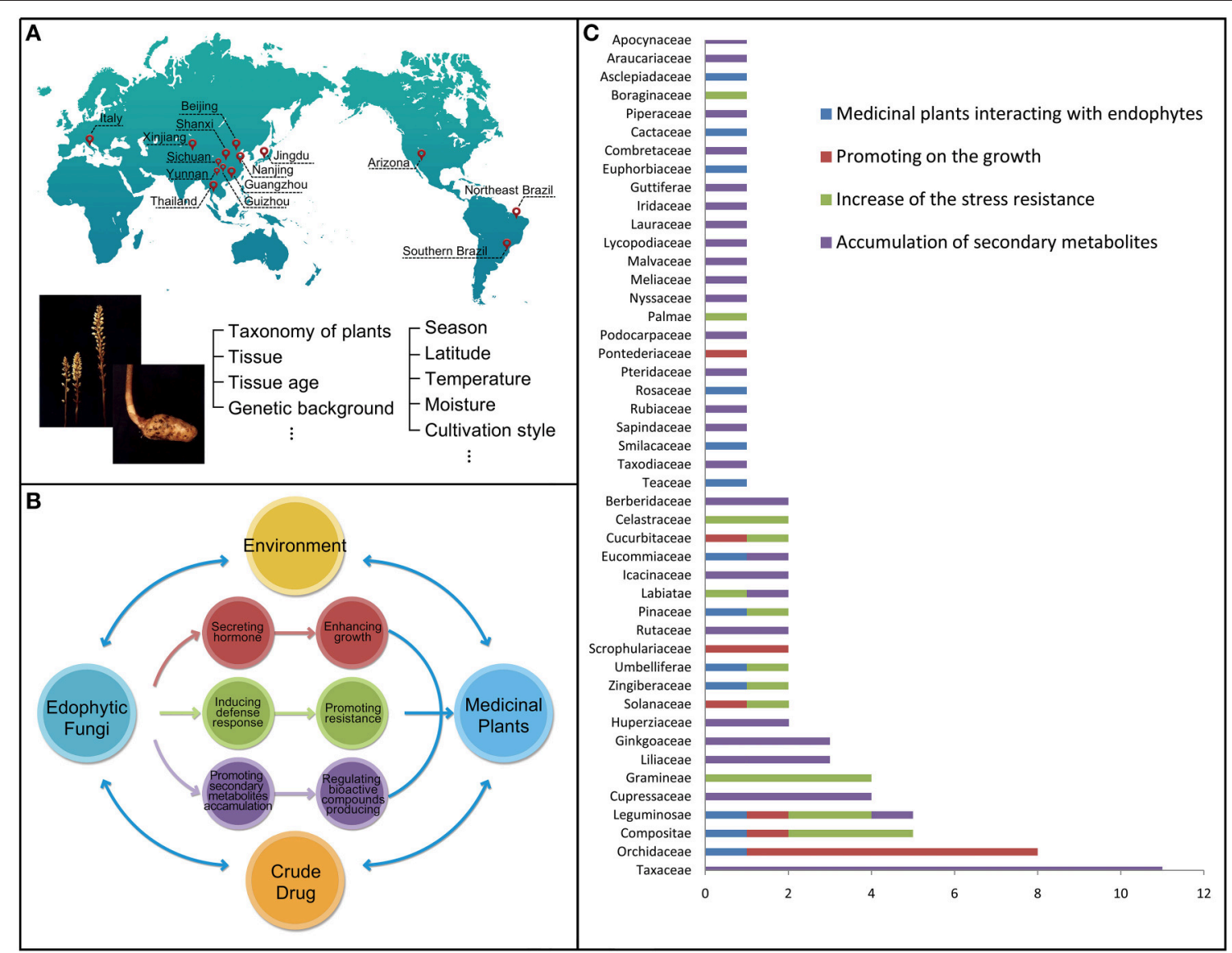

FIGURE 1 | The host-plant and environmental factors affecting the population structure and distribution of endophytic fungi (A). The beneficial relationships established by the endophytic fungi to their host medicinal plants including enhancing the growth and resistance of their host plants, as well as promoting the accumulation of secondary metabolites (B). Taxonomy of the total of 96 medicinal plant species involved in the reference survey and analysis for last 30 years ( $x$ axis: species numbers of the family; $y$ axis: the type of the family) (C).

could successfully grown. As a consequence, only a limited number of particular endophytic fungi could colonize in the corresponding host plants, resulting a certain degree of regional specificity on population structure of endophytic fungi (Jiang et al., 2010).

We also found that population structure of endophytic fungi normally represented a certain degree of regional specificity. The distribution of endophytic fungi from the same regions presented a high degree of similarity in terms of species taxonomy (D'Amico et al., 2008). Conversely, species and their population structure of endophytic fungi even in the same host plant species from different regions normally presented very low degree of similarity (Jiang et al., 2010).

\section{Influences of Genetic Background of Host Medicinal Plants on Population Structure of Endophytic Fungi}

The analysis of relationships between the host genotypes and symbiotic lifestyle expression further revealed that individual isolates of some endophytic fungal species could express either parasitic or mutualistic lifestyles, depending on the colonized host genotype (Redman et al., 2001; Unterseher and Schnittler, 2010). Accordingly, the fungus-host plant relationships should be regarded as flexible interaction, whose directionality was determined by slight differences in fungal gene expression in response to the host reaction, or conversely, by host recognition and response to the fungi. Hence, slight genetic differences in the genomes of both partners controlled the outcome (positive, negative, or neutral) of the symbiosis (Moricca and Ragazzi, 2008). Thus, population structure of endophytic fungi was considerably affected by the genetic background of host plants. Based on the facts indicated by the analyzed references that the fitness of the endophytic fungi largely depended on the fitness of the host medicinal plants, suggesting that the host plants largely determined the colonization and distribution of endophytic fungi in the host plants (Saikkonen et al., 2004).

Furthermore, phase disposition (age) of host plants and tissues may likewise influence species composition of the endophytic community (Sieber, 2007). For example, different endophyte species were found in different tissues such as parenquima, vascular ducts, and dermis of a host plant with different ages 
(Rodrigues, 1994). Such a specific distribution of endophytic species might be related to their ability to utilize specific substrates (Rodrigues, 1994). In addition, differential substrates utilized by different endophytic species demonstrated their resource distribution strategy when lived in the same organ of a host (Carroll and Petrini, 1983), reducing the competition between the endosymbionts. This indicated that the colonization of endophytic fungi was significantly determined by different plant tissues producing differential substrates.

\section{BENEFICIAL RELATIONSHIPS CONFERRED BY ENDOPHYTIC FUNGI TO HOST PLANTS}

Our analysis based on the selected references further indicated the benefits conferred by some endophytic fungi to their host plants after colonization. Such a beneficial interaction could be presented from three different aspects (Figure 1B). First, some endophytic fungi could produce different plant hormones to enhance the growth of their host plants (Waqas et al., 2012). For example, the growth of wheat (Triticum aestivum L.) could be enhanced by Azospirillum sp. under drought stresses (Dingle and McGee, 2003). Second, some endophytic fungi would produce different bioactive compounds, such as alkaloids, diterpenes, flavonoids, and isoflavonoids, to increase the resistance to biotic and abiotic stresses of their host plants (Firáková et al., 2007; Rodriguez et al., 2009). Third, some endophytic fungi could promote the accumulation of secondary metabolites (including important medicinal components or drugs) originally produced by plants. These metabolites may be produced by both of the host plants or/and endophytic fungi according to the references surveyed (Shwab and Keller, 2008). Owning to the importance of the three aspects, we would present the three types of possible beneficial endophytic fungus-host relationships accordingly.

\section{Classification of Host Medicinal Plants Interacting with Endophytic Fungi}

The reference survey and analysis showed that a total of 96 medicinal plant species were mutualisms, meaning mutual benefits, in terms of the fungus-host relationships (Tables 1-4). These species were distributed among 46 families (Figure 1C), including Apocynaceae (1 taxon), Araucariaceae (1 taxon), Asclepiadaceae (1 taxon), Berberidaceae (2 taxa), Boraginaceae (1 taxon), Cactaceae (1 taxon), Celastraceae (2 taxa), Combretaceae (1 taxon), Compositae (5 taxa), Cucurbitaceae (2 taxa), Cupressaceae (4 taxa), Eucommiaceae (2 taxa), Euphorbiaceae (1 taxon), Ginkgoaceae (3 taxa), Gramineae (4 taxa), Guttiferae (1 taxon), Huperziaceae (3 taxa), Icacinaceae (2 taxa), Iridaceae (1 taxon), Labiatae (2 taxa), Lauraceae (1 taxon), Leguminosae (5 taxa), Liliaceae (3 taxa), Lycopodiaceae (1 taxon), Malvaceae (1 taxon), Meliaceae (1 taxon), Nyssaceae (1 taxon), Orchidaceae (8 taxa), Palmae (1 taxon), Pinaceae (2 taxa), Piperaceae (1 taxon), Podocarpaceae (1 taxon), Pontederiaceae (1 taxon), Pteridaceae (1 taxon), Rosaceae (1 taxon), Rubiaceae (1 taxon), Rutaceae (2 taxa), Sapindaceae (1 taxon), Scrophulariaceae (2 taxa), Smilacaceae
(1 taxon), Solanaceae (3 taxa), Taxaceae (11 taxa), Taxodiaceae (1 taxon), Teaceae (1 taxon), Umbelliferae (2 taxa), and Zingiberaceae (2 taxa). The included plant species are commonly used as medicine either by direct consumption or for extracting bioactive components.

Obviously, these medicinal plant species from different families have their distribution in particular ecological habitats. Among these species, 16 species, such as Glycyrrhiza uralensis, Phellodendron amurense, and Rehmannia glutinosa etc. were mainly distributed in temperate regions, and 20 species, such as Amomum siamense, Cinchona ledgeriana, and Cinnamomum camphora chvar. Borneol etc. were only found in tropical regions. Forty species, such as Atractylodes lancea, Dysosma veitchii, and Salvia miltiorrhiza etc. were mainly distributed in subtropical regions. Four species, such as Apium graveolens and Foeniculum vulgare etc. were mainly distributed in Mediterranean region. Interestingly, some species were only found in extreme conditions, such as Cactus sp. in savanna deserts, Saussurea involucrata, Sinopodophyllum hexandrum, and Pedicularis sp. in high elevation.

The data obtained from the taxonomy of the total medicinal plants involved in the reference survey and analysis for last 30 years (Figure 1C) showed that the species associated with Taxaceae and Orchidaceae are higher than that of other family and accounted for 11 and 8, respectively.

Among the plants of family Taxaceae, all are related with endophytes which can produce taxol with antitumor activity. In 1993, an endophytic fungus, Taxomyces andreanae, was isolated from the bark of Taxus brevifolia and was shown to produce Taxol under in vitro axenic culture conditions (Stierle et al., 1993). Numerous reports are available on the pronounced variability in Taxol production from various endophytic fungal isolates across different batch cultures (Gangadevi and Muthumary, 2009). Paclitaxel (taxol) is a kind of diterpenoids American scientists isolated from the Pacific yew extract as a natural secondary metabolites in 1960s. It has significant anti-tumor activity, particularly ovarian cancer, uterine cancer, breast cancer with high incidence. So these important discoveries are worth further studying. Followed by the family Taxaceae, papers reporting Orchidaceae accounted of eight for the second highest reports and it has the potential to be developed further. Most of them are related with the endophytes which can promote on the growth of the host plants (Zhang J. et al., 1999; Guo and Wang, 2001). In nature, almost all orchid endophytic fungi invariably belong to the genus Rhizoctonia and are believed to be essential symbionts for both the germination of seeds and the development of the young heterotrophic plantlets. In most orchids the plant eventually becomes photosynthetic, while some species are known to remain heterotrophic throughout their life for providing nutrition to survive. The endophyte found in the adult plant is generally assumed to be the true symbiont of seeds and protocorms, and from the behavior of endophytes isolated from roots in culture with the host seeds various views have been put forward about specificity of the relationship between hosts and endophytes. Thus, it is of great importance to study the relationship between orchids and their endophytic fungi, as well as the plants of these two families. 


\section{Promotion of Fitness and Growth of Host Plants}

Results indicated that some endophytic fungi could increase the fitness and growth of host plants by increasing hormones, such as indole-3-acetic acid, indole-3-acetonitrile, and cytokinins. Endophytic fungi could also promote the growth of their host plants by obtaining nutritional elements such as nitrogen and phosphorus useful for plants (Zhang et al., 2006; Hartley and Gange, 2009). For example, Mycena dendrobii could promote the seed germination and growth of the host plant Gastrodia elata by secreting indoleacetic acid (Guo and Wang, 2001). In addition, Metarhizium robertsii translocated nitrogen directly from insects to its host plants through hyphae (Behie et al., 2012). Interestingly, results showed that most hormones were produced by endophytic fungi isolated from the roots of host plants. A few references also reported that some endophytic fungi could promote the growth and fitness of the host plants by activating the expression of a certain enzymes and genes (Chen et al., 2005). For example, Piriformospora indica increased the growth of tobacco roots by stimulating the expression of nitrate reductase and the starch-degrading enzyme (glucan-water dikinase) (Sherameti et al., 2005) (Table 2).

\section{Increase of Resistance to Stresses for Host Plants}

The references showed that certain endophytic fungi could enhance the resistance of host plants to biotic and abiotic stresses by producing bioactive compounds (chemicals) (Nejad and Johnson, 2000; Cavaglieri et al., 2004) (Table 3). In symbiotically conferred stress tolerance, the endophytic fungi were considered to act as a type of biological trigger that activated the defense systems of a host (Rodriguez and Redman, 2008). For example, endophytic fungi that were inoculated to crop plants improved the resistance and yield of the crops (Kozyrovska et al., 1996), and such a endophytic-mediated plant resistance to pathogens was more likely the result of direct competition between host plants and pathogens.

Interestingly, in many cases, the tolerance to biotic stresses was correlated with the bioactive compounds produced by endophytic fungi (Saikkonen et al., 1998; Tan and Zou, 2001; Zhang et al., 2006) that had antimicrobial activity against pathogens (Gunatilaka, 2006). Moreover, chemicals produced by endophytic fungi were toxic or distasteful to insects (Hartley and Gange, 2009), protecting the host plants from the attacks of insects. For example, alkaloids produced by endophytic fungi in the genus Neotyphodium could confer deterrence to their host plants, increasing their survival from the attacks by insects. With the increased stress tolerance, host plants infected by endophytic fungi could outcompete native plants without fungal infection, and consequently became invasive (Tofern et al., 1999; Clement et al., 2005).

In addition, endophytic fungi could produce a vast variety of antioxidant compounds (Table 3) that could protect their hosts by enhancing tolerance to abiotic stresses (HerreraCarrillo et al., 2009; Torres et al., 2009). In supporting of this, several studies had demonstrated increased production

TABLE 2 | Host medicinal plants with enhanced growth conferred by endophytic fungi.

\begin{tabular}{|c|c|c|c|}
\hline Host plant & Endophytic fungi & Mechanism & References \\
\hline Atracty lancea & Sclerotium sp. & $\begin{array}{l}\text { Increase cell protection from desiccationin and leaf } \\
\text { metabolic capability of host }\end{array}$ & Chen et al., 2008 \\
\hline Anoectochillus formosanus & Epulorhiza sp. & $\begin{array}{l}\text { Enhance four enzyme activities enzyme activities of } \\
\text { chitinase, } \beta-1,3 \text {-glucase, phenylalanine ammonia- lyase, } \\
\text { and polyphenoloxidase }\end{array}$ & Tang et al., 2008 \\
\hline Cymbidium sinense & Mycena orchdicola & Secret the plant hormones & Zhang J. et al., 1999 \\
\hline Dendrobium candidum & Mycena dendrobii & Secret the plant hormones & Zhang J. et al., 1999 \\
\hline Dendrobium nobile, D. chrysanthum & $\begin{array}{l}\text { Epulorhiza sp., Mycena sp., Tulasnellales, } \\
\text { Sebacinales, Cantharellales }\end{array}$ & $\begin{array}{l}\text { Enhance the absorption of nutrient in plants promoting } \\
\text { the seed germination of host }\end{array}$ & Chen and Guo, 2005 \\
\hline Monochoria vaginalis & Penicillium sp., Aspergillus sp. & Secret gibberellin & Ahmad et al., 2010 \\
\hline Pedicularis sp. & Dark septate endophytic fungi (DSEF) & Increase their nutrient utilization efficiency & Li and Guan, 2007 \\
\hline Rehmannia glutinosa & Ceratobasidium sp. & Secret indoleacetic acid & Chen B. et al., 2011 \\
\hline Nicotiana attenuata & Sebacina vermifera & $\begin{array}{l}\text { Enhance the absorption of nutrient and promote the } \\
\text { growth and fitness of by inhibiting ethylene signaling }\end{array}$ & Barazani et al., 2007 \\
\hline Sesbania sesban & $\begin{array}{l}\text { Funneliformis mosseae, Rhizophagus } \\
\text { intraradicesand Claroideoglomus etunicatum }\end{array}$ & Secret the plant hormones & Abd_Allah et al., 2015 \\
\hline
\end{tabular}


TABLE 3 | Host medicinal plants with enhanced defense responses conferred by endophytic fungi.

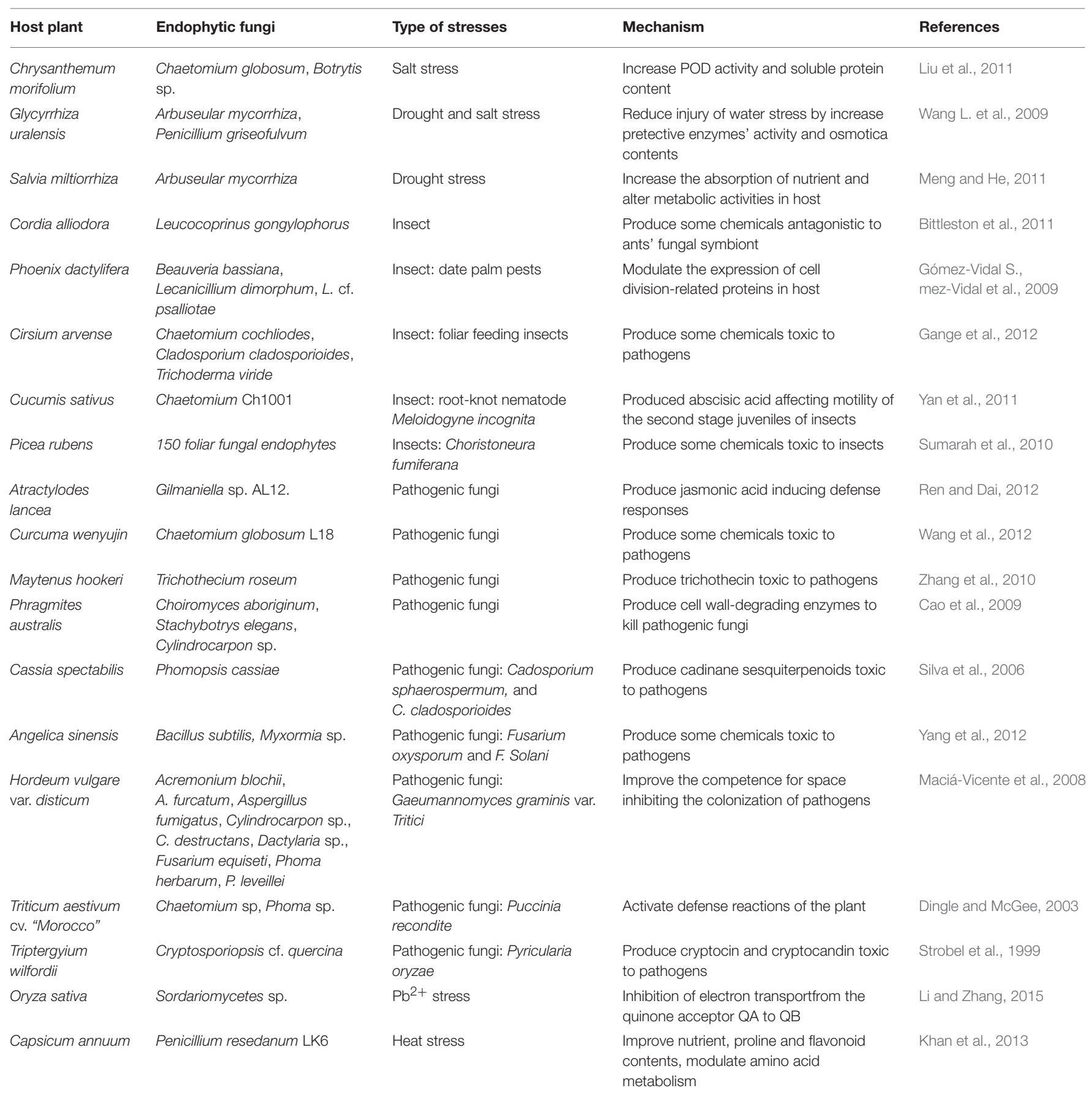

of antioxidant compounds (e.g., flavonoids and other phenolic antioxidants) in endophyte-infected plants (Richardson et al., 1992; Harper et al., 2003; Huang et al., 2007a,b). Furthermore, it was shown that endophytic fungi possessing metal sequestration or chelation systems were able to increase tolerances of their host plants to the presence of heavy metals, thereby, assisting their hosts to survive in contaminated soil (Weyens et al., 2009).

\section{Promoting the Accumulation of Bioactive Compounds of Medicinal Plants}

Results from our reference analyses clearly indicated that some endophytic fungi with ability promoted the accumulation of secondary metabolites of host plants, which influenced the quantity and quality of drugs (Chen et al., 2016). Some endophytic fungi could produce diverse classes of phytochemicals-secondary metabolites originally from plants, 
including the well-known compounds such as paclitaxel (also known as taxol) (Stierle et al., 1993), podophyllotoxin (Eyberger et al., 2006; Puri et al., 2006), deoxypodophyllotoxin (Kusari et al., 2009a), camptothecin, and structural analogs (Puri et al., 2005; Kusari et al., 2009c, 2011; Shweta et al., 2010), hypericin and emodin (Kusari et al., 2008, 2009b), and azadirachtin (Kusari et al., 2012) (Table 4). In fact, the best known example of anticancer compound taxol was found in the taxol-producing endophytic fungi $T$. andreanae that was isolated from $T$. brevifolia (Stierle et al., 1995). Many endophytic fungi colonized in other host plant species, such as Seimatoantlerium tepuiense, Seimatoantlerium nepalense (Bashyal, 1999), Tubercularia sp. strain TF5 (Wang J. et al., 2006), and Metarhizium anisopliae (Liu et al., 2009), were also found to produce taxol.

Other endophytic fungi could promote the formation and accumulation of secondary metabolites that were only produced by host plants. For example, Coetotrichum gloesporioides could induce the production of Artemisinin in hairy-root cultures of Artemisia annua (Wang J. W. et al., 2006). These compounds commonly function as bioactivities for antitumor, antipyretic, antimalarial, analgesic, or anti-inflammatory in medicinal treatments.

\section{CONCLUSION AND PERSPECTIVES}

This review highlights the environmental and host-plant factors that can possibly influence the population structure and distribution of endophytic fungi, as well as the benefits these endophtes provide to their host plants.

The fungus-host relationships reveal that the distribution and population structure of endophytic fungi rely largely on the taxonomy, genetic background, age, and tissues of the host plants, in addition to the types of environments. These findings can assist in the investigation of bioactive compounds produced by a certain host medicinal plant under specific environment conditions. In addition, we have observed that there are three types of beneficial interactions between endophytic fungi and their host plants namely: (1) enhancement of the growth of host medicinal plants, (2) increase in the resistance of the host plants to biotic and abiotic stresses, and (3) accumulation of secondary metabolites, including bioactive compounds used as drugs, produced originally by the medicinal plants. These findings have important practical implications for obtaining and producing drugs with improved quality and higher quantity.

Interestingly, genuine medicinal materials with the highest quality and best effects to a certain disease seems to have a special relationship with endophytic fungi. Special types of endophytic fungi of medicinal plants may be associated with the production of specific bioactive compounds needed by human. For example, a medicinal plant Huperzia serrata found in tropical region can produce Huperzine-A compounds that are considered being stimulated by endophytic fungi Acremonium sp. and Shiraia sp. (Wang Y. et al., 2009; Wang et al., 2011; Zhou et al., 2009). This is the reason why in traditional Chinese medicine, doctors prefer to use a particular medicinal plants from a particular geographical locations or habitats where the content and chemical types of particular compounds can be expected. Therefore, understanding the distribution and population structure patterns of endophytic fungi will provide a theoretical guide for effectively exploring bioactive compounds of drugs produced by a special host medicinal plant in particular tissues under special environment conditions.

Importantly, the application of target endophytic fungi can promote seed germination of many host plant species. The significance of this application can increase opportunities for the germination of those seeds that cannot germinate under the normal conditions. For example, seeds of some rare and endangered medicinal species, such as Dendrobium nobile and D. chrysanthum in the orchid family, are extremely difficult to geminate under normal conditions However, with the application of endophytic fungi in the genus Mycena, these seeds can germinate successfully, which has facilitated the artificial culture of these medicinal plants (Chen and Guo, 2005). This is particularly useful for the rare and endangered medicinal plants that are used in breeding programs where seed germination is crucial.

The most valuable application is to utilize the advantages of endophytic fungi that can promote the accumulation of secondary metabolites originally produced by plants. Through such an application, we can enhance the synthesis and accumulation of bioactive compounds of the host medicinal plants for higher quality of crude drugs, by adding particular endophytic fungi to the plants. This application may open a complete new dimension for the production of natural medicines in an extremely effective manner, given that the relationship between endophytic fungi and their host medicinal plants is completely understood.

Unfortunately, much of the work reported on the beneficial strains is confined to experimental studies, and more efforts should be put into field trials and applications to obtain higher-quality drugs. Also, the mechanisms of the interactions between endophytic fungi and their host plants have not been clearly defined. In addition, the research emphasis of endophyte need to be addressed over the next several decades, such as:

- Build a bioengineering system to mimick the mutualistic/antagonism symbiosis of endophytic fungi and their host plants, and facilitate the production of the bioactive compounds.

- Set up a guide for rapid screening of plant endophytic fungi beneficial to host plants other than isolate all strains uncritically.

- Establish target endophytic fungi library for plant breeding in order to protect the endangered medicinal plants by using seed germination.

- Solve the degradation problem of target endophytic fungi that can produce desired metabolites.

- Make better use of beneficial strains in planting and cultivating medicinal plants so the pharmaceutical products can be improved. 
TABLE 4 | Endophytic fungi producing plant-secondary metabolites in host plants.

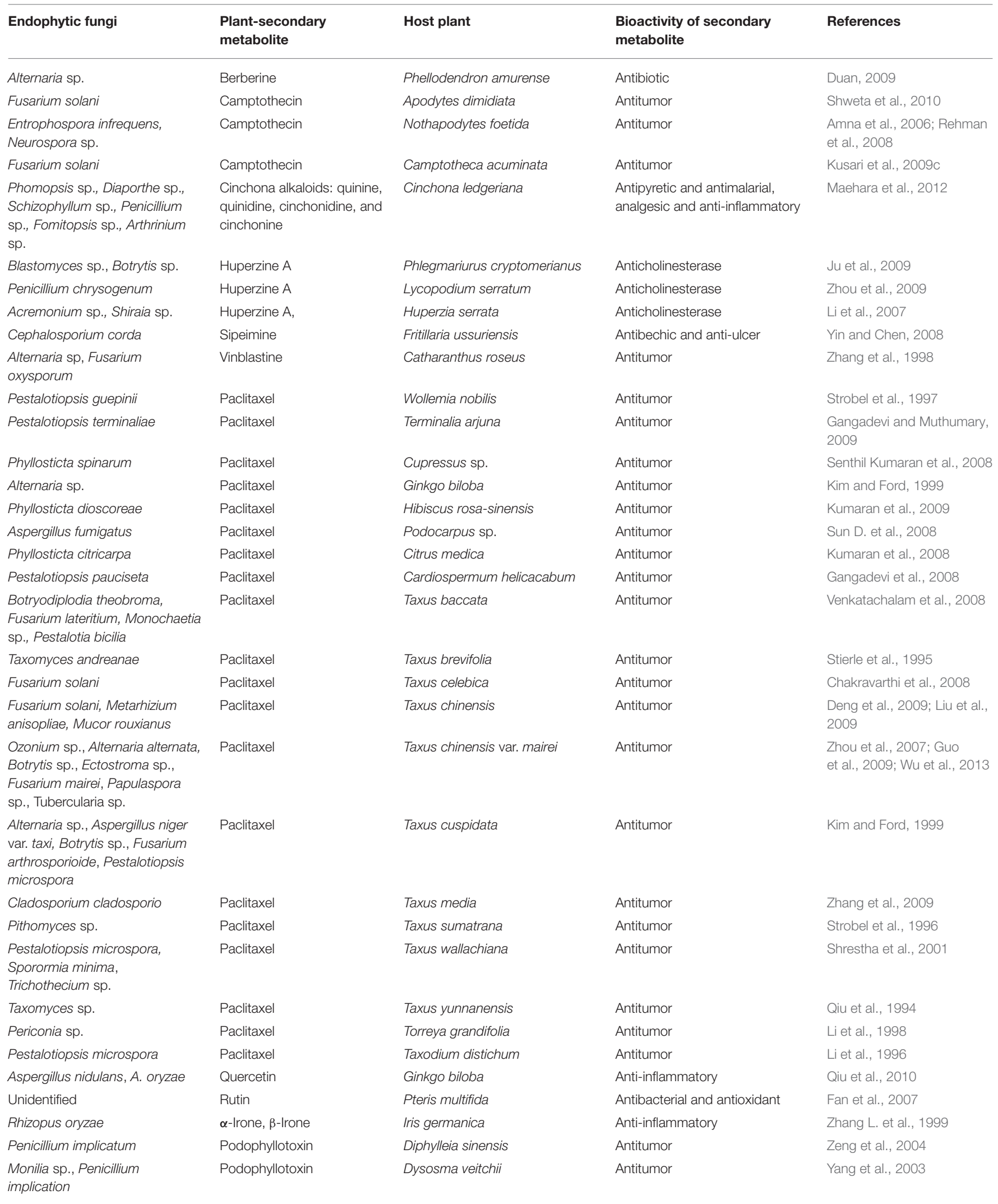


TABLE 4 | Continued

\begin{tabular}{|c|c|c|c|c|}
\hline Endophytic fungi & $\begin{array}{l}\text { Plant-secondary } \\
\text { metabolite }\end{array}$ & Host plant & $\begin{array}{l}\text { Bioactivity of secondary } \\
\text { metabolite }\end{array}$ & References \\
\hline $\begin{array}{l}\text { Penicillium sp., Phialocephala } \\
\text { fortinii, Trametes hirsuta, } \\
\text { Alternaria neesex }\end{array}$ & Podophyllotoxin & Sinopodophyllum hexandrum & Antitumor & Li, 2007 \\
\hline Fusarium oxysporum & Podophyllotoxin & Juniperus recurva & Antitumor & Kour et al., 2008 \\
\hline Alternaria sp. & Podophyllotoxin & Sabina vulgaris & Antitumor & Lu et al., 2006 \\
\hline Chaetomium globosum & Hypericin & Hypericum perforatum & Anti-depressant & Kusari et al., 2008 \\
\hline Trichoderma atroviride D16 & $\begin{array}{l}\text { Tanshinone IIA and } \\
\text { tanshinone I }\end{array}$ & Salvia miltiorrhiza & $\begin{array}{l}\text { Antibacterial and } \\
\text { anti-inflammatory }\end{array}$ & Ming et al., 2011 \\
\hline Sordariomycete sp. & Chlorogenic acid & Eucommia ulmoides & Antimicrobial and antitumor & Chen et al., 2010 \\
\hline $\begin{array}{l}\text { Cephalosporium sp., } \\
\text { Paecilomyces sp. }\end{array}$ & Diosgenin & Paris polyphylla var. yunnanensis & $\begin{array}{l}\text { Antitumor, anti-inflammatory, and } \\
\text { cardiovascular-protection }\end{array}$ & Cao et al., 2007 \\
\hline $\begin{array}{l}\text { Fusarium oxysporum, Neonectria } \\
\text { macrodidym, F. solani, F. } \\
\text { proliferatum }\end{array}$ & Cajaninstilbene acid & Cajanus cajan & $\begin{array}{l}\text { Antioxidant, hypotriglycerimic, } \\
\text { and hypoglycemic }\end{array}$ & Zhao et al., 2012 \\
\hline Cochliobolus nisikadoi & Borneol & $\begin{array}{l}\text { Cinnamomum camphora chvar. } \\
\text { Borneol }\end{array}$ & Anti-inflammatory, antioxidant & Chen M. et al., 2011 \\
\hline Fusarium oxysporum & Ginkgolide B & Ginkgo biloba & $\begin{array}{l}\text { Antishock, antiallergic, and } \\
\text { anti-inflammatory }\end{array}$ & Cui et al., 2012 \\
\hline Unidentified & Toosendanin & Melia azedarach & $\begin{array}{l}\text { Contact toxicity, stomach } \\
\text { toxicity, and anti-feeding }\end{array}$ & Zhao et al., 2011 \\
\hline Fusarium redolens & $\begin{array}{l}\text { Peimisine and } \\
\text { imperialine-3 } \beta \text {-D-glucoside }\end{array}$ & $\begin{array}{l}\text { Fritillaria unibracteata var. } \\
\text { wabuensis }\end{array}$ & $\begin{array}{l}\text { Get rid of sputum, cough, and } \\
\text { antitumor }\end{array}$ & Pan et al., 2015 \\
\hline Colletotrichum gloeosporioides & Piperine & Piper nigrum & $\begin{array}{l}\text { Antimicrobial, antidepressant, } \\
\text { anti-inflammatory, and anticancer }\end{array}$ & Chithra et al., 2014 \\
\hline
\end{tabular}

Such knowledge can be well exploited and applied for obtaining better drugs from medicinal plants. We believe that this review provides new insights into drug discovery and clinical utility which can be further improved by investigating endophytes further as these have the potential of playing a key front line role in the treatment of various diseases.

\section{AUTHOR CONTRIBUTIONS}

Reviewed and finalized manuscript: TH, LQ; Completed the article writing: MJ, LC; Integrated information of tables, analyzed data, and made pictures: HX, CZ; Took charge of the manuscript language: KR.

\section{ACKNOWLEDGMENTS}

This work was supported by the Young Scientist Special Project of the National High Technology Research and Development Program of China (No. 2014AA020508) and National Natural Science Foundation of China (No. 81573599, 81473301, 81403162, 815 73696).

\section{REFERENCES}

Abd_Allah, E. F., Hashem, A., Alqarawi, A. A., Bahkali, A. H., and Alwhibi, M. S. (2015). Enhancing growth performance and systemic acquired resistance of medicinal plant Sesbania sesban (L.) Merr using arbuscular mycorrhizal fungi under salt stress. Saudi. J. Biol. Sci. 22, 274-283. doi: 10.1016/j.sjbs.2015.03.004

Ahmad, N., Hamayun, M., Khan, S. A., Khan, A. L., Lee, I. J., and Shin, D. H. (2010). Gibberellin-producing endophytic fungi isolated from Monochoria vaginalis. J. Microbiol. Biotechnol. 20, 1744-1749. doi: 10.4014/jmb.1005.05018

Amna, T., Puri, S. C., Verma, V., Sharma, J. P., Khajuria, R. K., Musarrat, J., et al. (2006). Bioreactor studies on the endophytic fungus Entrophospora infrequens for the production of an anticancer alkaloid camptothecin. Can. J. Microbiol. 52, 189-196. doi: 10.1139/W05-122

Bacon, C. W., and White, J. (2000). Microbial Endophytes. New York, NY: CRC.

Barazani, O., von Dahl, C. C., and Baldwin, I. T. (2007). Sebacina vermifera promotes the growth and fitness of Nicotiana attenuata by inhibiting ethylene signaling. Plant. Physiol. 144, 1223-1232. doi: 10.1104/pp.107.097543
Bashyal, B. (1999). Seimatoantlerium nepalense, an endophytic taxol producing coelomycete from Himalayan yew (Taxus wallachiana). Mycotaxon 72, 33-42.

Behie, S. W., Zelisko, P. M., and Bidochka, M. J. (2012). Endophytic insectparasitic fungi translocate nitrogen directly from insects to plants. Science 336, 1576-1577. doi: 10.1126/science.1222289

Bittleston, L. S., Brockmann, F., Wcislo, W., and Van Bael, S. A. (2011). Endophytic fungi reduce leaf-cutting ant damage to seedlings. Biol. Lett. 7, 30-32. doi: $10.1098 / \mathrm{rsbl} .2010 .0456$

Bussaban, B., Lumyong, S., Lumyong, P., McKenzie, E. H., and Hyde, K. D. (2001). Endophytic fungi from Amomum siamense. Can. J. Microbiol. 47, 943-948. doi: 10.1139/w01-098

Camatti-Sartori, V., da Silva-Ribeiro, R. T., Valdebenito-Sanhueza, R. M., Pagnocca, F. C., Echeverrigaray, S., and Azevedo, J. L. (2005). Endophytic yeasts and filamentous fungi associated with southern Brazilian apple (Malus domestica) orchards subjected to conventional, integrated or organic cultivation. J. Basic Microb. 45, 397-402. doi: 10.1002/jobm.2004 10547 
Cao, R., Liu, X., Gao, K., Mendgen, K., Kang, Z., Gao, J., et al. (2009). Mycoparasitism of endophytic fungi isolated from reed on soilborne phytopathogenic fungi and production of cell wall-degrading enzymes in vitro. Curr. Microbiol. 59, 584-592. doi: 10.1007/s00284-009-9477-9

Cao, X., Li, J., and Zhou, L. (2007). Determination of diosgenin content of the endophytic fungi from Paris polyphylla var. yunnanensis by using an optimum ELISA. Nat. Prod. Res. Dev. 19, 1020-1023. doi: 10.3969/j.issn.10016880.2007.06.025

Carroll, G., and Petrini, O. (1983). Patterns of substrate utilization by some fungal endophytes from coniferous foliage. Mycologia 75, 53-63. doi: 10.2307/3792923

Cavaglieri, L., Passone, A., and Etcheverry, M. (2004). Correlation between screening procedures to select root endophytes for biological control of Fusarium verticillioides in Zea mays L. Biol. Control. 31, 259-267. doi: 10.1016/j.biocontrol.2004.07.006

Chakravarthi, B. V., Das, P., Surendranath, K., Karande, A. A., and Jayabaskaran, C. (2008). Production of paclitaxel by Fusarium solani isolated from Taxus celebica. J. Biosci. 33, 259-267. doi: 10.1007/s12038-008-0043-6

Chen, B., Wang, M., Hu, Y., Lin, Z., Yu, R., and Huang, L. (2011). Preliminary study on promoting effects of endophytic fungi to growth of Rehmannia glutinosa. Chin. J. Chin. Mater. Med. 36, 1137-1140. doi: $10.4268 / \mathrm{cjcmm} 20110906$

Chen, J. X., Dai, C. C., Li, X., Tian, L. S., and Xie, H. (2008). Endophytic fungi screening from Atracty lancea and inoculating into the host plantlet. Guihaia 28, 256-260. doi: 10.3969/j.issn.1000-3142.2008.02.022

Chen, L., Zhang, Q. Y., Jia, M., Ming, Q. L., Yue, W., Rahman, K., et al. (2016). Endophytic fungi with antitumor activities: Their occurrence and anticancer compounds. Crit. Rev. Microbiol. 42, 454-473. doi: 10.3109/1040841X.2014.959892

Chen, M., Yang, L., Li, Q., Shen, Y., Shao, A., Lin, S., et al. (2011). Volatile metabolites analysis and molecular identification of endophytic fungi bn 12 from Cinnamomum camphora chvar. borneol. Chin. J. Chin. Mater. Med. 36, 3217-3221. doi: 10.4268/cjcmm20112301

Chen, X., Guo, S., and Wang, C. (2005). Effects of four endophytic fungi on the growth and polysaccharide content of Anoectochilus roxburghii (Wall.) Lindl. Chin. Pharm. J. 40, 13-16. doi: 10.3321/j.issn:1001-2494.2005.01.006

Chen, X., Sang, X., Li, S., Zhang, S., and Bai, L. (2010). Studies on a chlorogenic acid-producing endophytic fungi isolated from Eucommia ulmoides Oliver. J. Ind. Microbiol. Biotechnol. 37, 447-454. doi: 10.1007/s10295-010-0690-0

Chen, X. M., and Guo, S. X. (2005). Effects of four species of endophytic fungi on the growth and polysaccharide and alkaloid contents of Dendrobium nobile. Chin. J. Chin. Mater. Med. 30, 253-257. doi: 10.3321/j.issn:10015302.2005.04.003

Chithra, S., Jasim, B., Sachidanandan, P., Jyothis, M., and Radhakrishnan, E. K. (2014). Piperine production by endophytic fungus Colletotrichum gloeosporioides isolated from Piper nigrum. Phytomedicine 21, 534-540. doi: 10.1016/j.phymed.2013.10.020

Chutima, R., Dell, B., Vessabutr, S., Bussaban, B., and Lumyong, S. (2011). Endophytic fungi from Pecteilis susannae (L.) Rafin (Orchidaceae), a threatened terrestrial orchid in Thailand. Mycorrhiza 21, 221-229. doi: 10.1007/s00572010-0327-1

Clement, S. L., Elberson, L. R., Bosque-Pérez, N. A., Wang, B., and Elberson, L. R. (2005). Detrimental and neutral effects of wild barley-Neotyphodium fungal endophyte associations on insect survival. Entomol. exp. Appl. 114, 119-125. doi: 10.1111/j.1570-7458.2005.00236.x

Cui, Y., Yi, D., Bai, X., Sun, B., Zhao, Y., and Zhang, Y. (2012). Ginkgolide B produced endophytic fungus (Fusarium oxysporum) isolated from Ginkgo biloba. Fitoterapia 83, 913-920. doi: 10.1016/j.fitote.2012.04.009

Dai, C. C., Yu, B. Y., Xu, Z. L., and Yuan, S. (2003). Effect of environmental factors on growth and fatty acid composition of five endophytic fungi from Sapium sebiferum. J. Appl. Ecol. 14, 1525-1528.

D'Amico, M., Frisullo, S., and Cirulli, M. (2008). Endophytic fungi occurring in fennel, lettuce, chicory, and celery-commercial crops in southern Italy. Mycol. Res. 112, 100-107. doi: 10.1016/j.mycres.2007.11.007

Deng, B. W., Liu, K. H., Chen, W. Q., Ding, X. W., and Xie, X. C. (2009). Fusarium solani, Tax-3, a new endophytic taxol-producing fungus from Taxus chinensis. World J. Microb. Biotechnol. 25, 139-143. doi: 10.1007/s11274-0089876-2
Dingle, J., and McGee, P. A. (2003). Some endophytic fungi reduce the density of pustules of Puccinia recondita f. sp. tritici in wheat. Mycol. Res. 107, 310-316. doi: $10.1017 /$ S0953756203007512

Duan, L. (2009). Isolation and identification of producing endophytic fungi of berberine from the plant Phellodendron amurense. J. Anhui. Agric. Sci. 22, 007. doi: 10.3969/j.issn.0517-6611.2009.22.007

Eyberger, A. L., Dondapati, R., and Porter, J. R. (2006). Endophyte fungal isolates from Podophyllum peltatum produce podophyllotoxin. J. Nat. Prod. 69, 1121-1124. doi: 10.1021/np060174f

Faeth, S. H., and Fagan, W. F. (2002). Fungal endophytes: common host plant symbionts but uncommon mutualists. Integr. Comp. Biol. 42, 360-368. doi: $10.1093 / \mathrm{icb} / 42.2 .360$

Fan, Y., Zhan, S., Chen, Y., Gan, J. L., Peng, Q., Liu, Z. J., et al. (2007). Study on endophytic fungi of Pteris multifida II: a preliminary study on a strain of Rutin-producing endophytic fungi. J. Fung. Res. 4, 008. doi: 10.3969/j.issn.16723538.2007.04.007

Firáková, S., Šturdíková, M., and Múčková, M. (2007). Bioactive secondary metabolites produced by microorganisms associated with plants. Biologia 62, 251-257. doi: 10.2478/s11756-007-0044-1

Gangadevi, V., and Muthumary, J. (2009). Taxol production by Pestalotiopsis terminaliae, an endophytic fungus of Terminalia arjuna (arjun tree). Biotechnol. Appl. Biochem. 52, 9-15. doi: 10.1042/BA20070243

Gangadevi, V., Murugan, M., and Muthumary, J. (2008). Taxol determination from Pestalotiopsis pauciseta, a fungal endophyte of a medicinal plant. Chin. J. Biotechnol. 24, 1433-1438. doi: 10.1016/S1872-2075(08)60065-5

Gange, A. C., Eschen, R., Wearn, J. A., Thawer, A., and Sutton, B. C. (2012). Differential effects of foliar endophytic fungi on insect herbivores attacking a herbaceous plant. Oecologia 168, 1023-1031. doi: 10.1007/s00442-011-2151-5

Gao, X. X., Zhou, H., Xu, D. Y., Yu, C. H., Chen, Y. Q., and Qu, L. H. (2006). High diversity of endophytic fungi from the pharmaceutical plant, Heterosmilax japonica Kunth revealed by cultivation-independent approach. FEMS Microbiol. Lett. 249, 255-266. doi: 10.1016/j.femsle.2005.06.017

Gómez-Vidal S., mez-Vidal, S., Salinas, J., Tena, M., and Lopez-Llorca, L. V. (2009). Proteomic analysis of date palm (Phoenix dactylifera L.) responses to endophytic colonization by entomopathogenic fungi. Electrophoresis 30, 2996-3005. doi: 10.1002/elps.200900192

Gunatilaka, A. A. (2006). Natural products from plant-associated microorganisms: distribution, structural diversity, bioactivity, and implications of their occurrence. J. Nat. Prod. 69, 509-526. doi: 10.1021/np058128n

Guo, B. H., Wang, Y. C., Zhou, X. W., Hu, K., Tan, F., Miao, Z. Q., et al. (2009). An endophytic taxol-producing fungus BT2 isolated from Taxus chinensis var. mairei. Afr. J. Biotechnol. 5, 875-877.

Guo, L. D., Huang, G. R., and Wang, Y. (2008). Seasonal and tissue age influences on endophytic fungi of Pinus tabulaeformis (Pinaceae) in the Dongling Mountains, Beijing. J. Integr. Plant. Biol. 50, 997-1003. doi: 10.1111/j.17447909.2008.00394.x

Guo, S. X., and Wang, Q. Y. (2001). Character and action of good strain on stimulating seed germination of Gastrodia elata. Mycosystema 3, 408-412. doi: 10.3969/j.issn.1672-6472.2001.03.023

Harper, J. K., Arif, A. M., Ford, E. J., Strobel, G. A., Porco, J. A., Tomer, D. P., et al. (2003). Pestacin: a 1,3-dihydro isobenzofuran from Pestalotiopsis microspora possessing antioxidant and antimycotic activities. Tetrahedron 59, 2471-2476. doi: 10.1016/S0040-4020(03)00255-2

Hartley, S. E., and Gange, A. C. (2009). Impacts of plant symbiotic fungi on insect herbivores: mutualism in a multitrophic context. Annu. Rev. Entomol. 54, 323-342. doi: 10.1146/annurev.ento.54.110807.090614

Herrera-Carrillo, Z., Torres, M. S., Singh, A. P., Vorsa, N., Gianfagna, T., Meyer, W., et al. (2009). "Phenolic, flavonoid and antioxidant profiling for cool-Season grasses with and without endophytes," in Eighteenth Annual Rutgers Turfgrass Symposium 2009 (New Brunswick, NJ), 43.

Huang, W. Y., Cai, Y. Z., Hyde, K. D., Corke, H., and Sun, M. (2007a). Endophytic fungi from Nerium oleander L (Apocynaceae): main constituents and antioxidant activity. World J. Microb. Biotechnol. 23, 1253-1263. doi: 10.1007/s11274-007-9357-Z

Huang, W. Y., Cai, Y. Z., Xing, J., Corke, H., and Sun, M. (2007b). A potential antioxidant resource: endophytic fungi from medicinal plants. Econ. Bot. 61, 14-30. doi: 10.1663/0013-0001(2007)61[14:APAREF]2.0.CO;2 
Jiang, S., Duan, J. A., Tao, J. H., Yan, H., and Zheng, J. B. (2010). Ecological distribution and elicitor activities of endophytic fungi in Changium smyrnioides. Chin. Tradit. Herb. Drugs 1, 121-125.

Ju, Z., Wang, J., and Pan, S. L. (2009). Isolation and preliminary identification of the endophytic fungi which produce Hupzine A from four species in Hupziaceae and determination of Huperzine A by HPLC. J. Med. Sci. 36, 445-449. doi: 10.3969/j.issn.1672-8467.2009.04.015

Khan, A. L., Kang, S. M., Dhakal, K. H., Hussain, J., Adnan, M., Kim, J. G., et al. (2013). Flavonoids and amino acid regulation in Capsicum annuum L. by endophytic fungi under different heat stress regimes. Sci. Hortic. 155, 1-7. doi: $10.1016 /$ j.scienta.2013.02.028

Kim, S. U., and Ford, E. (1999). Screening of taxol-producing endophytic fungi from Ginkgo biloba and Taxus cuspidata in Korea. Nat. Prod. Organic. Chem. 42, 97-99.

Kour, A., Shawl, A. S., Rehman, S., Sultan, P., Qazi, P. H., Suden, P., et al. (2008). Isolation and identification of an endophytic strain of Fusarium oxysporum producing podophyllotoxin from Juniperus recurva. World. J. Microb. Biot. 24, 1115-1121. doi: 10.1007/s11274-007-9582-5

Kozyrovska, N., Kovtunovych, G., Gromosova, E., Kuharchuk, P., and Kordyum, V. (1996). Novel inoculants for an environmentally-friendly crop production. Resour. Conserv. Recy. 18, 79-85. doi: 10.1016/S0921-3449(96)01170-6

Kumaran, R. S., Muthumary, J., and Hur, B. K. (2008). Taxol from Phyllosticta citricarpa, a Leaf Spot Fungus of the Angiosperm citrus medica. J. Biosci. Bioeng. 106, 103-106. doi: 10.1263/jbb.106.103

Kumaran, R. S., Muthumary, J., Kim, E. K., and Hur, B. K. (2009). Production of taxol from Phyllosticta dioscoreae, a leaf spot fungus isolated from Hibiscus rosa-sinensis. Biotechnol. Bioprocess. Eng. 14, 76-83. doi: 10.1007/s12257-0080041-4

Kusari, S., Lamshöft, M., and Spiteller, M. (2009a). Aspergillus fumigatus Fresenius, an endophytic fungus from Juniperus communis L. Horstmann as a novel source of the anticancer pro-drug deoxypodophyllotoxin. J. Appl. Microbiol. 107, 1019-1030. doi: 10.1111/j.1365-2672.2009.04285.x

Kusari, S., Lamshöft, M., Zühlke, S., and Spiteller, M. (2008). An endophytic fungus from Hypericum perforatum that produces hypericin. J. Nat. Prod. 71, 159-162. doi: $10.1021 / \mathrm{np} 070669 \mathrm{k}$

Kusari, S., Verma, V. C., Lamshoeft, M., and Spiteller, M. (2012). An endophytic fungus from Azadirachta indica A. Juss. that produces azadirachtin. World J. Microbiol. Biotechnol. 28, 1287-1294. doi: 10.1007/s11274-011-0876-2

Kusari, S., Zühlke, S., Kosuth, J., Cellárová, E., and Spiteller, M. (2009b). Lightindependent metabolomics of endophytic Thielavia subthermophila provides insight into microbial hypericin biosynthesis. J. Nat. Prod. 72, 1825-1835. doi: 10.1021/np9002977

Kusari, S., Zühlke, S., and Spiteller, M. (2009c). An endophytic fungus from Camptotheca acuminata that produces camptothecin and analogues. J. Nat. Prod. 72, 2-7. doi: 10.1021/np800455b

Kusari, S., Zühlke, S., and Spiteller, M. (2011). Effect of artificial reconstitution of the interaction between the plant Camptotheca acuminata and the fungal endophyte Fusarium solani on camptothecin biosynthesis. J. Nat. Prod. 74, 764-775. doi: 10.1021/np1008398

Li, A. R., and Guan, K. Y. (2007). Mycorrhizal and dark septate endophytic fungi of Pedicularis species from northwest of Yunnan Province, China. Mycorrhiza 17, 103-109. doi: 10.1007/s00572-006-0081-6

Li, C. (2007). Fermentation conditions of Sinopodophyllum hexandrum endophytic fungus on production of podophyllotoxin. Food. Ferment. Ind. 33, 28-32.

Li, J. Y., Strobel, G., Sidhu, R., Hess, W. M., and Ford, E. J. (1996). Endophytic taxol-producing fungi from bald cypress, Taxodium distichum. Microbiology 142, 2223-2226. doi: 10.1099/13500872-142-8-2223

Li, J. Y., Sidhu, R. S., Ford, E. J., Long, D. M., Hess, W. M., and Strobel, G. A. (1998). The induction of taxol production in the endophytic fungus-Periconia sp from Torreya grandifolia. J. Ind. Microbiol. Biotechnol. 20, 259-264. doi: $10.1038 /$ sj.jim. 2900521

Li, W. K., Zhou, J. Y., Lin, Z. W., and Hu, Z. (2007). Study on fermentation condition for production of huperzine A from endophytic fungus $2 \mathrm{~F} 09 \mathrm{P} 03 \mathrm{~B}$ of Huperzia serrata. Chin. J. Med. Chem. 2, 254-259.

$\mathrm{Li}, \mathrm{X}$., and Zhang, L. (2015). Endophytic infection alleviates $\mathrm{Pb}^{2+}$ stress effects on photosystem II functioning of Oryza sativa leaves. J. Hazard. Mater. 295, 79-85. doi: 10.1016/j.jhazmat.2015.04.015
Liu, K., Ding, X., Deng, B., and Chen, W. (2009). Isolation and characterization of endophytic taxol-producing fungi from Taxus chinensis. J. Ind. Microbiol. Biotechnol. 36, 1171-1177. doi: 10.1007/s10295-009-0598-8

Liu, X. Z., Song, W. L., Zhang, K., Ye, Y. C., and Dai, C. C. (2011). Effects of two Kinds of endophytic fungi infection on water stress of seedlings of Chrysanthemum morifolium. Acta Hortic. Sin. 38, 335-342.

Lu, L., He, J., Yu, X. P., Li, G. Z., and Zhang, X. (2006). Studies on isolation and identification of endophytic fungi strain SC13 from harmaceutical plant Sabina vulgaris Ant. and metabolites. Acta Agric. Boreali Occidentalis Sin. 15, 85-89. doi: 10.3969/j.issn.1004-1389.2006.05.021

Maciá-Vicente, J., Jansson, H., Mendgen, K., and Lopez-Llorca, L. V. (2008). Colonization of barley roots by endophytic fungi and their reduction of take-all caused by Gaeumannomyces graminis var. tritici. Can. J. Microbiol. 54, 600-609. doi: 10.1139/W08-047

Maehara, S., Simanjuntak, P., Maetani, Y., Kitamura, C., Ohashi, K., and Shibuya, H. (2012). Ability of endophytic filamentous fungi associated with Cinchona ledgeriana to produce Cinchona alkaloids. J. Nat. Med. 67, 421-423. doi: 10.1007/s11418-012-0701-8

Meng, J. J., and He, X. L. (2011). Effects of AM fungi on growth and nutritional contents of Salvia miltiorrhiza Bge. under drought stress. J. Agric. Univ. Hebei. 34, 51-55. doi: 10.3969/j.issn.1000-1573.2011.01.011

Ming, Q. L., Han, T., Li, W. C., Zhang, Q., Zhang, H., Zheng, C., et al. (2011). Tanshinone IIA and tanshinone I production by Trichoderma atroviride D16, an endophytic fungus in Salvia miltiorrhiza. Phytomedicine 15, 330-333. doi: 10.1016/j.phymed.2011.09.076

Mo, L., Kang, J. C., He, J., Cao, J. J., and Su, H. (2008). A freliminary study on composition of endophytic fungi from Gastrodia elata. J. Fung. Res. 6, 211-215.

Moricca, S., and Ragazzi, A. (2008). Fungal endophytes in Mediterranean oak forests: a lesson from Discula quercina. Phytopathology 98, 380-386. doi: 10.1094/PHYTO-98-4-0380

Nascimento, T. L., Oki, Y., Lima, D. M. M., Almeida-Cortez, J. S., Fernandes, G. W., and Souza-Motta, C. M. (2015). Biodiversity of endophytic fungi in different leaf ages of Calotropis procera and their antimicrobial activity. Fungal. Ecol. 14, 79-86. doi: 10.1016/j.funeco.2014.10.004

Nejad, P., and Johnson, P. A. (2000). Endophytic bacteria induce growth promotion and wilt disease suppression in oilseed rape and tomato. Biol. Control. 18, 208-215. doi: 10.1006/bcon.2000.0837

Osono, T. (2008). Endophytic and epiphytic phyllosphere fungi of Camellia japonica: seasonal and leaf age-dependent variations. Mycologia 100, 387-391. doi: 10.3852/07-110R1

Pan, B. F, Su, X., Hu, B., Yang, N., Chen, Q., and Wu, W. (2015). Fusarium redolens $6 \mathrm{WBY} 3$, an endophytic fungus isolated from Fritillaria unibracteata var. wabuensis, produces peimisine and imperialine-3 $\beta$-d-glucoside. Fitoterapia 103, 213-221. doi: 10.1016/j.fitote.2015.04.006

Puri, S. C., Nazir, A., Chawla, R., Arora, R., Riyaz-Ul-Hasan, S., Amna, T., et al. (2006). The endophytic fungus Trametes hirsuta as a novel alternative source of podophyllotoxin and related aryl tetralin lignans. J. Biotechnol. 122, 494-510. doi: 10.1016/j.jbiotec.2005.10.015

Puri, S. C., Verma, V., Amna, T., Qazi, G. N., and Spiteller, M. (2005). An endophytic fungus from Nothapodytes foetida that produces camptothecin. J. Nat. Prod. 68, 1717-1719. doi: 10.1021/np0502802

Qiu, D., Huang, M., Fang, X., Zhu, C., and Zhu, Z. (1994). Isolation of an endophytic fungus associated with Taxus yunnanensis Cheng et LK Fu. Acta Mycol. Sin. 13, 314.

Qiu, M., Xie, R., Shi, Y., Zhang, H., and Chen, H. (2010). Isolation and identification of two flavonoid-producing endophytic fungi from Ginkgo biloba L. Ann. Microbiol. 60, 143-150. doi: 10.1007/s13213-010-0016-5

Redman, R. S., Dunigan, D. D., and Rodriguez, R. J. (2001). Fungal symbiosis from mutualism to parasitism: who controls the outcome, host or invader? New Phytol. 151, 705-716. doi: 10.1046/j.0028-646x.2001.00210.x

Rehman, S., Shawl, A., Verma, V., Kour, A., Athar, M., Andrabi, R., et al. (2008). An endophytic Neurospora sp. from Nothapodytes foetida producing camptothecin. Prikl. Biokhim. Mikrobiol. 44, 225-231. doi: 10.1134/s0003683808020130

Ren, C. G., and Dai, C. C. (2012). Jasmonic acid is involved in the signaling pathway for fungal endophyte-induced volatile oil accumulation of Atractylodes lancea plantlets. BMC Plant. Biol. 12:128. doi: 10.1186/1471-2229-12-128 
Richardson, M. D., Chapman, G. W., Hoveland, C. S., and Bacon, C. W. (1992). Sugar alcohols in endophyte-infected tall fescue under drought. Crop. Sci. 32, 1060-1061. doi: 10.2135/cropsci1992.0011183X003200040045x

Rodrigues, K. F. (1994). The foliar fungal endophytes of the Amazonian palm Euterpe oleracea. Mycologia 86, 376-385. doi: 10.2307/37 60568

Rodriguez, R., and Redman, R. (2008). More than 400 million years of evolution and some plants still can't make it on their own: plant stress tolerance via fungal symbiosis. J. Exp. Bot. 59, 1109-1114. doi: 10.1093/jxb/erm342

Rodriguez, R. J., White, J. F. Jr., Arnold, A. E., and Redman, R. S. (2009). Fungal endophytes: diversity and functional roles. New Phytol. 182, 314-330. doi: 10.1111/j.1469-8137.2009.02773.x

Saikkonen, K., Faeth, S. H., Helander, M., and Sullivan, T. J. (1998). Fungal endophytes: a continuum of interactions with host plants. Ann. Rev. Ecol. Syst. 29, 319-343. doi: 10.1146/annurev.ecolsys.29.1.319

Saikkonen, K., Wäli, P., Helander, M., and Faeth, S. H. (2004). Evolution of endophyte-plant symbioses. Trends Plant. Sci. 9, 275-280. doi: 10.1016/j.tplants.2004.04.005

Senthil Kumaran, R., Muthumary, J., and Hur, B. (2008). Production of Taxol from Phyllosticta spinarum, an endophytic fungus of Cupressus sp. Eng. Life Sci. 8, 438-446. doi: 10.1002/elsc.200800019

Sherameti, I., Shahollari, B., Venus, Y., Altschmied, L., Varma, A., and Oelmüller, R. (2005). The endophytic fungus Piriformospora indica stimulates the expression of nitrate reductase and the starch-degrading enzyme glucanwater dikinase in tobacco and Arabidopsis roots through a homeodomain transcription factor that binds to a conserved motif in their promoters. J. Biol. Chem. 280, 26241-26247. doi: 10.1074/jbc.M500447200

Shrestha, K., Strobel, G. A., Shrivastava, S. P., and Gewali, M. B. (2001). Evidence for paclitaxel from three new endophytic fungi of Himalayan yew of Nepal. Planta. Med. 67, 374-376. doi: 10.1055/s-2001-14307

Shwab, E. K., and Keller, N. P. (2008). Regulation of secondary metabolite production in filamentous ascomycetes. Mycol. Res. 112, 225-230. doi: 10.1016/j.mycres.2007.08.021

Shweta, S., Zuehlke, S., Ramesha, B. T., Priti, V., Kumar, P. M., Ravikanth, G., et al. (2010). Endophytic fungal strains of Fusarium solani, from Apodytes dimidiata E. Mey. ex Arn (Lcacinaceae) produce camptothecin, 10-hydroxycamptothecin and 9-methoxycamptothecin. Phytochemistry 71, 117-122. doi: 10.1016/j.phytochem.2009.09.030

Sieber, T. N. (2007). Endophytic fungi in forest trees: are they mutualists? Fung. Biol. Rev. 21, 75-89. doi: 10.1016/j.fbr.2007.05.004

Silva, G. H., Teles, H. L., Zanardi, L. M., Young, M. C. M., Eberlin, M. N., Hadad, R., et al. (2006). Cadinane sesquiterpenoids of Phomopsis cassiae, an endophytic fungus associated with Cassia spectabilis (Leguminosae). Phytochemistry 67, 1964-1969. doi: 10.1016/j.phytochem.2006.06.004

Song, S., Otkur, M., Zhang, Z., and Tang, Q. (2007). Isolation and characterization of endophytic microorganisms in Glaycyrrhiza inflat Bat. from Xinjiang. Microbiology 5, 867-870. doi: 10.3969/j.issn.0253-2654.2007.05.010

Stierle, A., Strobel, G., and Stierle, D. (1993). Taxol and taxane production by Taxomyces andreanae, an endophytic fungus of Pacific yew. Science 260, 214-216. doi: 10.1126/science.8097061

Stierle, A., Strobel, G., Stierle, D., Grothaus, P., and Bignami, G. (1995). The search for a taxol-producing microorganism among the endophytic fungi of the Pacific yew, Taxus brevifolia. J. Nat. Prod. 58, 1315-1324. doi: 10.1021/np50123a002

Strobel, G. A., Hess, W. M., Ford, E., Sidhu, R. S., and Yang, X. (1996). Taxol from fungal endophytes and the issue of biodiversity. J. Ind. Microbiol. Biotechnol. 17, 417-423. doi: 10.1007/BF01574772

Strobel, G. A., Hess, W. M., Li, J. Y., Ford, E., Sears, J., Sidhu, R. S., et al. (1997). Pestalotiopsis guepinii, a taxol-producing endophyte of the wollemi pine, Wollemia nobilis. Aust. J. Bot. 45, 1073-1082. doi: 10.1071/BT96094

Strobel, G. A., Miller, R. V., Martinez-Miller, C., Condron, M. M., Teplow, D. B., and Hess, W. M. (1999). Cryptocandin, a potent antimycotic from the endophytic fungus Cryptosporiopsis cf. quercina. Microbiology 145, 1919-1926. doi: 10.1099/13500872-145-8-1919

Sumarah, M. W., Puniani, E., Sørensen, D., Blackwell, B. A., and Miller, J. D. (2010). Secondary metabolites from anti-insect extracts of endophytic fungi isolated from Picea rubens. Phytochemistry 71, 760-765. doi: 10.1016/j.phytochem.2010.01.015
Sun, D., Ran, X., and Wang, J. (2008). Isolation and identification of a taxolproducing endophytic fungus from Podocarpus. Acta Microbiol. Sin. 48, 589-595. doi: 10.3321/j.issn:0001-6209.2008.05.005

Sun, J., Guo, L., Zang, W., Ping, W., and Chi, D. (2008). Diversity and ecological distribution of endophytic fungi associated with medicinal plants. Sci. China. C Life. Sci. 51, 751-759. doi: 10.1007/s11427-008-0091-z

Suryanarayanan, T. S., Wittlinger, S. K., and Faeth, S. H. (2005). Endophytic fungi associated with cacti in Arizona. Mycol. Res. 109, 635-639. doi: $10.1017 /$ S0953756205002753

Tan, R. X., and Zou, W. X. (2001). Endophytes: a rich source of functional metabolites. Nat. Prod. Rep. 18, 448-459. doi: 10.1039/b100918o

Tang, M. J., Meng, Z. X., Guo, S. X., Chen, X. M., and Xiao, P. G. (2008). Effects of endophytic fungi on the culture and four enzyme activities of Anoectochilus roxburghii. Chin. Pharm. J. 43, 890-893. doi: 10.3321/j.issn:10012494.2008.12.003

Tofern, B., Kaloga, M., Witte, L., Hartmann, T., and Eich, E. (1999). Occurrence of loline alkaloids in Argyreia mollis (Convolvulaceae). Phytochemistry 51, 1177-1180. doi: 10.1016/S0031-9422(99)00121-1

Torres, M. S., Singh, A. P., Shah, S., Herrera-Carrillo, Z., Gianfagna, T., White, J. F. Jr., et al. (2009). "LC-MS-MS identification and quantification of phenolics in symbiotic tall fescue," in Paper presented at the Proceedings of the 18th Annual Rutgers Turfgrass Symposium (New Brunswick, NJ).

Unterseher, M., and Schnittler, M. (2010). Species richness analysis and ITS rDNA phylogeny revealed the majority of cultivable foliar endophytes from beech (Fagus sylvatica). Fung. Ecol. 3, 366-378. doi: 10.1016/j.funeco.2010.03.001

Venkatachalam, R., Subban, K., and Paul, M. J. (2008). Taxol from Botryodiplodia theobromae (BT 115)-An endophytic fungus of Taxus baccata. J. Biotechnol. 136, S189-S190. doi: 10.1016/j.jbiotec.2008.07.1823

Wang, J., Li, G., Lu, H., Zheng, Z., Huang, Y., and Su, W. (2006). Taxol from Tubercularia sp. strain TF5, an endophytic fungus of Taxus mairei. FEMS Microbiol. Lett. 193, 249-253. doi: 10.1111/j.1574-6968.2000.tb09432.x

Wang, J. W., Zheng, L. P., and Xiang, T. R. (2006). The Preparation of an elicitor from a fungal endophyte to enhance Artemisinin production in hairy root cultures of Artemisia annua L. Chin. J. Biotechnol. 22, 829-834. doi: 10.3321/j.issn:1000-3061.2006.05.023

Wang, L., Liu, L., and Han, S. Z. (2009). Screening and identification of antimicrobe activity of endophytic fungus in Glycyrrhiza uralensis. Biotechnol. Bull. 6, 034.

Wang, Y., Dai, C. C., and Chen, Y. (2009). Antimicrobial activity of volatile oil from Atractylodes lancea against three species of endophytic fungi and seven species of exogenous fungi. J. Appl. Ecol. 20, 2778-2784.

Wang, Y., Xu, L., Ren, W., Zhao, D., Zhu, Y., and Wu, X. (2012). Bioactive metabolites from Chaetomium globosum L18, an endophytic fungus in the medicinal plant Curcuma wenyujin. Phytomedicine 19, 364-368. doi: 10.1016/j.phymed.2011.10.011

Wang, Y., Zeng, Q. G., Zhang, Z. B., Yan, R. M., Wang, L. Y., and Zhu, D. (2011). Isolation and characterization of endophytic huperzine A-producing fungi from Huperzia serrata. J. Ind. Microbiol. Biotechnol. 38, 1267-1278. doi: 10.1007/s10295-010-0905-4

Waqas, M., Khan, A. L., Kamran, M., Hamayun, M., Kang, S. M., Kim, Y. H., et al. (2012). Endophytic fungi produce gibberellins and indoleacetic acid and promotes host-plant growth during stress. Molecules 17, 10754-10773. doi: 10.3390/molecules 170910754

Weyens, N., van der Lelie, D., Taghavi, S., and Vangronsveld, J. (2009). Phytoremediation: plant-endophyte partnerships take the challenge. Curr. Opin. Biotechnol. 20, 248-254. doi: 10.1016/j.copbio.2009.02.012

Wu, L., Han, T., Li, W., Jia, M., Xue, L., Rahman, K., et al. (2013). Geographic and tissue influences on endophytic fungal communities of Taxus chinensis var. mairei in China. Curr. Microbiol. 66, 40-48. doi: 10.1007/s00284-012-0235-z

Yan, X. N., Sikora, R. A., and Zheng, J. W. (2011). Potential use of cucumber (Cucumis sativus $\mathrm{L}$.) endophytic fungi as seed treatment agents against rootknot nematode Meloidogyne incognita. J. Zhejiang. Univ. Sci. B 12, 219-225. doi: 10.1631/jzus.B1000165

Yang, N. Y., Jiang, S., Shang, E. X., Tang, Y. P., and Duan, J. A. (2012). A new phenylpentanamine alkaloid produced by an endophyte Bacillus subtilis isolated from Angelica sinensis. J. Chem. Res. 36, 647-647. doi: 10.3184/174751912X13469254685262 
Yang, X., Guo, S., Zhang, L., and Shao, H. (2003). Select of producing podophyllotoxin endophytic fungi from podophyllin plant. Nat. Prod. Res. Dev. 5, 419-422. doi: 10.3969/j.issn.1001-6880.2003.05.012

Yin, H., and Chen, J. L. (2008). Sipeimine-producing endophytic fungus isolated from Fritillaria ussuriensis. Z. Naturforsch. C 63, 789. doi: 10.1515/znc-200811-1202

Yu, X. M., and Guo, S. X. (2000). Establishment of symbiotic system for Anoectochilus roxburghii (Wall.) Lindl. and endophytic fungi. Chin. J. Chin. Mater. Med. 25, 81-83. doi: 10.3321/j.issn:1001-5302.2000.02.006

Zeng, S., Shao, H., and Zhang, L. (2004). An endophytic fungus producing a substance analogous to podophyllotoxin isolated from Diphylleia sinensis. J. Microbiol. 24, 1-2. doi: 10.3969/j.issn.1005-7021.2004.04.001

Zhang, H. W., Song, Y. C., and Tan, R. X. (2006). Biology and chemistry of endophytes. Nat. Prod. Rep. 23, 753-771. doi: 10.1039/b609472b

Zhang, J., Wang, C., Guo, S., Chen, J., and Xiao, P. (1999). Studies on the plant hormones produced by 5 species of endophytic fungi isolated from medicinal plants (Orchidacea). Acta Acad. Med. Sin. 21, 460-465.

Zhang, L., Gu, S., Shao, H., and Wei, R. (1999). Isolation determination and aroma product characterization of fungus producing irone. Mycosystema 18, 49-54.

Zhang, L. Q., Guo, B., and Li, H. Y. (1998). Isolation of an fungus producting Vinbrastine. J. Yunnan. Univ. (Nat. Sci.) 20, 214-215.

Zhang, P., Zhou, P. P., and Yu, L. J. (2009). An endophytic taxol-producing fungus from Taxus media, Cladosporium cladosporioides MD2. Curr. Microbiol. 59, 227-232. doi: 10.1007/s00284-008-9270-1

Zhang, X., Li, G., Ma, J., Zeng, Y., Ma, W., and Zhao, P. (2010). Endophytic fungus Trichothecium roseum LZ93 antagonizing pathogenic fungi in vitro and its secondary metabolites. J. Microbiol. 48, 784-790. doi: 10.1007/s12275-0100173-z

Zhao, J., Fu, Y., Luo, M., Zu, Y., Wang, W., Zhao, C., et al. (2012). Endophytic fungi from pigeon pea [Cajanus cajan (L.) Millsp.] produce antioxidant cajaninstilbene acid. J. Agric. Food Chem. 60, 4314-4319. doi: 10.1021/jf205097y

Zhao, J., Shan, T., Mou, Y., and Zhou, L. (2011). Plant-derived bioactive compounds produced by endophytic fungi. Mini Rev. Med. Chem. 11, 159-168. doi: 10.2174/138955711794519492

Zhou, S. L., Yang, F., Lan, S. L., Xu, N., and Hong, Y. H. (2009). Huperzine A producing conditions from endophytic fungus in SHB Huperzia Serrata. J. Microbiol. 3, 32-36. doi: 10.3969/j.issn.1005-7021.2009.03.006

Zhou, X., Wang, Z., Jiang, K., Wei, Y., Lin, J., Sun, X., et al. (2007). Screening of taxol-producing endophytic fungi from Taxus chinensis var. mairei. Prikl. Biokhim. Mikrobiol. 43, 490-494. doi: 10.1134/s000368380704014x

Conflict of Interest Statement: The authors declare that the research was conducted in the absence of any commercial or financial relationships that could be construed as a potential conflict of interest.

Copyright (c) 2016 Jia, Chen, Xin, Zheng, Rahman, Han and Qin. This is an openaccess article distributed under the terms of the Creative Commons Attribution License (CC BY). The use, distribution or reproduction in other forums is permitted, provided the original author(s) or licensor are credited and that the original publication in this journal is cited, in accordance with accepted academic practice. No use, distribution or reproduction is permitted which does not comply with these terms. 